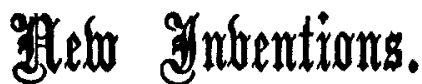

\section{AN INK WRITING.POINT ATTACHMENT FOR DUDGEON'S SPHYGMOGRAPH.}

THIS simple little device for obtaining sphygmographic records in ink on a clean white paper may recommend itself to those who have found that the usual method is apt to prove rather a troublesome matter anywhere where the facilities for smoking the paper, varnishing it, and spreading it out to dry are less readily accessible than in hospital practice. It consists in a fine capillary glass tube drawn into the shape of the letter $L$, the longer limb of which fits on to the writing lever of a sphygmograpb, whilst the shorter limb is drawn out to a fine point and serves as a writing point. Several such glass writing points can be carried in the case of the sphygmograph, together with a small bottle of writing fluid, so that the operator may have the choice on each occasion on which the sphygmograph is to be used of taking the tracing in ink on a white paper, or by the usual method on a smoked one. When the former method is to be employed all that is necessary is to select a glass writing point, thrust down its longer limb the end of the writing lever of the sphygmograph, moisten the writing point with a drop of ink, adjust the paper, and start the clockwork. The writing point, which sucks up by capillary force enough ink to write two or three tracings each six inches long, is most conveniently charged by applying to it a paint-brush wet with the ink just before starting the clockwork. After

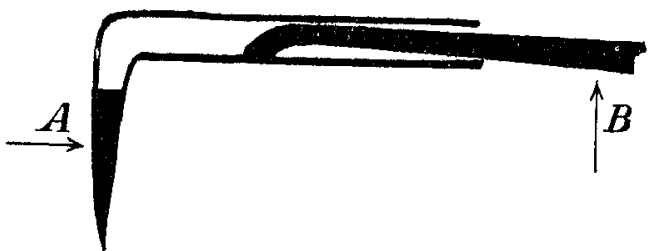

A, Writing point.

B, Writing lever.

taking the tracing it is wise to drain the writing point on to a piece of blotting-paper so as to avoid clogging of the point. By this method the tracings are taken as a black line at once, thus obviating any necessity of printing the records by photo. graphy for purposes of reproduction : it does away with the necessity for soot and varnish, for the tracings are dry as soon as they are written and can be carried away at once in the waistcoat pocket. These writing-points have been made for me from my pattern by Messrs. Down Bros., Limited, 21, St. Thomas's-street, London, S.K. J. W. ScotT MACFIE. Oxford.

AN IMPROVED TRACHOMA FORCEPS.

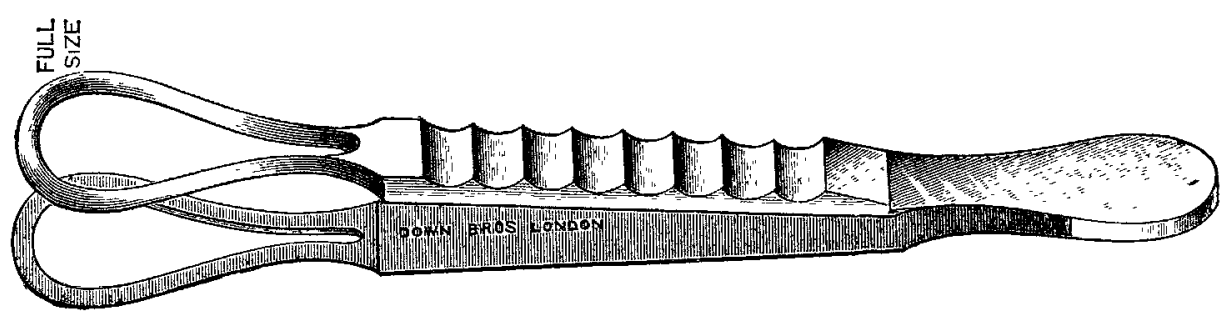

OF the two forms of forceps for the removal of trachomatous granules or "sago grains," those of Grady and Knapp, the former may be considered to cause somewhat less bruising but has the drawback, especially in unruly children, of occasion. ally catching in the eyelid. Messrs. Down Bros. have lately made me an improved pattern with closed ends, which gets over this difficulty with complete success.

Chepstow. J. CROPPER, M.D. Cantab.

\section{ROYAL COLLEGE OF PHYSICIANS OF LONDON.}

a Comitia was held on April 30th, Sir Richard Douglas PowELL, Bart., K.C.V.O., the President, being in the chair.

The following gentlemen having passed the requisite examination were admitted Members of the College:Robert Alexander Chisolm, M.A., M.B. Oxon. ; James Clark, M.D. Aberd. ; Thomas Bogie Hamilton, M.B. Edin. ; Eardley Lancelot Holland, M.D. Lond., L.R.C.P. Lond.; James Mackenzie, M.D. Edin.; Alexander Manuel, M.B. Lond., L.R.C.P. Lond. ; Richard John Morris, M.D. Durh., L.R.O.P. Lond. ; and John Norman Walker, Captain, I.M.S., L.R.C.P. Lond.

Licences to practise physic were granted to 103 gentlemen who had passed the required examinations.

The PResidennt announced that he had received a letter from the treasurer of the Royal College of Physicians of Edinburgh announcing the death of Dr. Charles E. Underhill, President of that College. It was resolved that a letter should be addressed to the Fellows of that College condoling with them on the loss which they had sustained.

A report was received from the examiners for the Murchison scholarship, and the same was awarded to Edward Leslie Martyn Lobb, a student of Gray's Hospital. The recipient was congratulated by the PrESIDENT. The same examiners (Dr. S. J. SHARKEY and Dr. W. HALE WhITE) moved the following proposition :-

That a committee be appointed to consider by what means the competition for the Murchison scholarship may be increased.

The motion was carried and the following Fellows were appointed to form the committee : Dr. S. J. Sharkey, Dr. W. Hale White, Dr. Lauriston E. Shaw, Dr. H. P. Hawkins, and Dr. J. A. Ormerod.

The following Members were elected as Fellows of the College : Robert Charles Brown, M.B. Lond. ; George Ogilvie, M.B. Edin. ; Charles Henry Cattle, M. D. Lond. ; John Elliott, M.D. Lond.; Guthrie Rankin, M.D. Glasg. ; Theodore Fisher, M.D. Lond.; Robert James McLean Buchanan, M.D. Vict. Arthur Francis Stabb, M.B. Camb.; William Henry Butter Stoddart, M.D. Lond. ; Arthur Latham Ormerod, M.D. Oxon.;
Walter Langdon Brown, M.D. Cantab. ; Alfred Ernest Russell, M.D. Lond. ; Reginald Cecil Bligh Wall, M.D. Oxon.; Thomas Wardrop Griffith, M.D. Aberd.; and Leonard Stanley Dadgeon.

The following communications were received: 1. From the secretary of the Royal College of Surgeons of England reporting proceedings of its Council on April 9th. 2. From the secretary of the Royal College of Surgeons in Ireland thanking the College for its letter and resolution of March 20th. 3. From the registrar of the University of Wales (new Faculty of Medicine) inviting the College to appoint a representative to serve as a member of the Medical Board. The invitation was accepted and it was left to the President to nominate a Fellow to act as a representative. 4. From the secretary of the Society of Arts, giving notice of the award of the Swiney Prize, jointly by the Society and the College, in January next, for the best published work on Medical Jurisprudence.

A report was received and adopted from the Pharmacopceia Committee, which was appointed on Jan. 30th, 1908, in response to an invitation to the College from the President of the General Medical Council to assist in the revision of the British Pharmacopceia of 1898.

The President then dissolved the Comitia.

VICTORIA UNIVERSITY OF MANCHESTER.-The council of the University having decided on the appointment of a second professor in the department of medicine, one of the chairs will be devoted to clinical medicine and the other to systematic medicine. Dr. Graham Steell, now professor of medicine in the University and senior physician in the Royal Infirmary, will hold the chair of clinical medicine, and Dr. George R. Murray, who until recently held the Heath professorship of comparative pathology in the University of Durham, bas been appointed professor of systematic medicine. Under the agreement entered into between the University and the Royal Infirmary Dr. Murray becomes on his appointment a member of the honorary stafl of the Royal Infirmary. It is expected that he will undertake the duties of the chair in the University at the beginning of next session and at the infirmary when the new buildings are opened. 